\title{
Debating Phenomenological Research Methods
}

Linda Finlay, Open University

Email: linda@lindafinlay.co.uk

\section{Abstract}

Phenomenological researchers generally agree that our central concern is to return to embodied, experiential meanings aiming for a fresh, complex, rich description of a phenomenon as it is concretely lived. Yet debates abound when it comes to deciding how best to carry out this phenomenological research in practice. Confusion about how to conduct appropriate phenomenological research makes our field difficult for novices to access. Six particular questions are contested: (1) How tightly or loosely should we define what counts as "phenomenology"? (2) Should we always aim to produce a general (normative) description of the phenomenon, or is idiographic analysis a legitimate aim? (3) To what extent should interpretation be involved in our descriptions? (4) Should we set aside or bring to the foreground researcher subjectivity? (5) Should phenomenology be more science than art? (6) Is phenomenology a modernist or postmodernist project, or neither? In this paper, I examine each of these areas of contention in the spirit of fostering dialogue, and promoting openness and clarity in phenomenological inquiry.

\section{Introduction}

Phenomenological philosophers have been "extraordinarily diverse in their interests, in their interpretation of the central issues of phenomenology, in their application of what they understood to be the phenomenological method, and in their development of what they took to be the phenomenological programme for the future of philosophy" (Moran, 2000 , p. 3). This diversity finds reflection in phenomenological research, where the application of philosophical ideas to the empirical project provokes both uncertainty and controversy.

Phenomenological researchers generally agree that our central concern is to return to embodied, experiential meanings. We aim for fresh, complex, rich descriptions of a phenomenon as it is concretely lived. As Wertz (2005) puts it: "Phenomenology is a lowhovering, in-dwelling, meditative philosophy that glories in the concreteness of personworld relations and accords lived experience, with all its indeterminancy and ambiguity, primacy over the known” (p. 175). There is a general consensus that we need 
phenomenological research methods that are responsive to both the phenomenon and the subjective interconnection between the researcher and the researched.

That said, we continue to engage in a spirited debate about how to do phenomenological research in practice. While this debate is healthy, tensions are occasionally created in our community by unduly critical debate where confusion about what constitutes appropriate or "sound" phenomenological research makes our field difficult for novices to access. When commitment to shared scholarly exploration is displaced by dogmatic assertion, both the quality and the potential of phenomenological inquiry are threatened.

Six particular questions are contested: (1) How tightly or loosely should we define what counts as phenomenology? (2) Should we always aim to produce a general (normative) description of the phenomenon or is idiographic analysis a legitimate aim? (3) To what extent should interpretation be involved in our descriptions? (4) Should we set aside or bring to the foreground researcher subjectivity? (5) Should phenomenology be more science than art? (6) Is phenomenology a modernist or postmodernist project, or neither? In this paper, I examine each of these areas of contention in the spirit of fostering dialogue and promoting openness and clarity in phenomenological inquiry. Mills (2003) cautions: “To prosper and advance, it becomes important for any discipline to evaluate its theoretical and methodological propositions from within its own evolving framework rather than insulate itself from criticism due to threat or cherished group loyalties” (p. 150).

\section{What Counts as "Phenomenology"?}

Many different research methods and techniques are practiced under the banner of phenomenological research. What are the boundaries, the defining characteristics, of phenomenology? What distinguishes our work from other variants of qualitative research that focus on subjective meanings?

Focusing specifically on psychological phenomenological approaches ${ }^{1}$, Giorgi (1989) has stated that four core characteristics hold across all variations: The research is rigorously descriptive, uses the phenomenological reductions, explores the intentional relationship between persons and situations, and discloses the essences, or structures, of meaning immanent in human experiences through the use of imaginative variation. Elsewhere Giorgi (1997), more straightforwardly, argues that the phenomenological method encompasses three interlocking steps: (1) phenomenological reduction, (2) description, and (3) search for essences.

Yet, variations in phenomenological methodology flourish. Some adhere reasonably closely to Giorgi's framework based on the reduction and imaginative variation while, at the same time, offering their own emphases (e.g., the open lifeworld approach of Dahlberg et al. 2008; van Manen's, lived experience human science inquiry based on University of Utrecht tradition, 1990; the dialogal approach, Halling et al., 2006; the Dallas approach, Garza 2007; Todres' embodied lifeworld approach, 2005, 2007; and Ashworth's, lifeworld approach, 2003, 2006).

There also exist a number of phenomenological methods which focus on rich descriptions of lived experience and meanings, but which do not explicitly use Husserlian 
techniques such as eidetic variation. Smith's Interpretative Phenomenological Analysis (IPA), which has gained considerable purchase in the qualitative psychology field in the United Kingdom, is one such example. Smith argues that his idiographic and inductive method, which seeks to explore participants' personal lived experiences, is phenomenological in its concern for individuals' perceptions. He also, however, identifies more strongly with hermeneutic traditions which recognize the central role played by the researcher, and does not advocate the use of bracketing (Smith, 2004).

The debate about whether or not a method is in fact phenomenological pivots on the issue of criteria. Specifically, is it sufficient to strive for rich description of lived experience, or are additional aspects required such as having a special phenomenological stance or attitude? Is Giorgi's Husserl-inspired method the template against which other versions should be measured? When Giorgi (2008a, p. 34) states that he does not consider the ways some colleagues have adapted his own basic method with wider variations to be sound - from either a research or phenomenological perspective-is he more tightly ringfencing the psychological phenomenological project? In fact, in an earlier paper, Giorgi is clear that his method is neither exclusive nor exhaustive and that it should not be considered paradigmatic (Giorgi, 1975). His complaint would appear to be directed against researchers who either claim their work derives from Husserl when primary sources have not been read or understood, or against researchers who evoke Giorgi's own name and method falsely, thereby misrepresenting his work. More recently, Giorgi (2008b) has critiqued students' illogical tendency to lay claim to ideas stemming from philosophers/methodologists who have irreconcilable differences.

My own position on this question is that phenomenological research is phenomenological when it involves both rich description of the lifeworld or lived experience, and where the researcher has adopted a special, open phenomenological attitude which, at least initially, refrains from importing external frameworks and sets aside judgements about the realness of the phenomenon. Put another way, I support Husserl's idea that varying modes of "givenness" can only be unfurled through the reduction and, as Marion (2002) puts it, with more reduction we get more givenness.

I also think that researchers should be clear about which philosophical and/or research traditions they are following. I have concerns about research which purports to be Husserlian, for example, when there is no evidence of any reductions being attempted. Similarly, researchers who claim to have bracketed and, therefore, transcended their assumptions while using a hermeneutic approach would seem to be both naïve and confused.

In my view, a phenomenological method is sound if it links appropriately to some phenomenological philosophy or theory, and if its claims about method are justified and consistent. For example, in a recently published paper, six researchers (including myself) apply different approaches to-versions of-phenomenology (King et al, 2008). We regard ourselves as practicing phenomenologically based empirical work as distinct from engaging a philosophical reflection on "things in their appearing" in the philosophical sense. While there are commonalities in our methods of analyses and findings, we also diverge; but in this divergence, we link explicitly and reflexively back to different theoretical/philosophical commitments.

It is perhaps helpful to recognize that a number of qualitative approaches to research have borrowed and built upon phenomenological philosophy and techniques. As Wertz 
(2005) says, a genuinely psychological qualitative method implicitly uses the descriptive psychological reflection so characteristic of the phenomenological approach. In such cases, it is perhaps best to view research which does not fully embrace the phenomenological project's commitment to description, and the researcher having an open phenomenological attitude (if not actually applying specific reductions), as phenomenologically inspired or phenomenologically orientated. Any research which does not have at its core the description of "the things in their appearing," focusing on experience as lived, cannot be considered phenomenological.

\section{General Description or Idiographic Analysis?}

Phenomenologists contest what should be the focus of their research. Many, like Giorgi (following Husserl), seek to throw light on the essential and general structures of a phenomenon. One version of this approach is to explicitly focus on the lifeworld, which is seen to be a human universal consisting of essential features (e.g., Dahlberg et al. 2008; Todres, Galvin and Dahlberg 2006; Ashworth, 2003, 2006). ${ }^{2}$ A variant of lifeworld research is a reflective and practical focus on lived experience adopted by many in the pedagogic (see van Manen, 1990) and health care fields (e.g., see Crotty's 1996 review of nursing research). Other phenomenologists concentrate on the narratives emerging from data; Langdridge (2008) and his Critical Narrative Approach following Ricoeur is one example.

With these different approaches, the phenomenon in question varies subtly. For instance, in researching the topic of anxiety, one could explore the lifeworld of a person who is anxious; another could aim to explore the general structure (or essence) of the lived experience of "being anxious"; yet another could explore the stories people tell of their experience of feeling anxious. Underlying these different approaches, with their varying points of focus, are questions that ask to what extent the phenomenology practiced aims to describe the experience in general (i.e., as one shared by many), or is it instead focused on explicating individual experience?

Giorgi (2008a) is clear that the purpose of the method he has developed is to clarify the nature of the phenomenon being studied in a more traditional, normative, and scientific sense. He recommends recruiting at least three participants, arguing that the differences between them make it easier to discern the individual experience from the more general experience of the phenomenon. As he puts it: "At least three participants are included because a sufficient number of variations are needed in order to come up with a typical essence” (Giorgi, p. 37). In Giorgi's method, idiographic analysis may form part of the process of analysis but the eventual aim is to explicate-eidetically-the phenomenon as a whole regardless of the individuals concerned. Idiographic details are thus discarded or typified and generalized.

In contrast, other phenomenologists explicitly seek out idiographic meanings in an attempt to understand the individual which may or may not offer general insights. In the United Kingdom, the work of Ashworth (e.g., Ashworth, 2006; King et al., 2008) is notable here, as are the contributions of those using Interpretative Phenomenological Analysis (for instance, Smith and Osborn, 2003; Eatough and Smith, 2006). For my part, I have also favored an approach with a strong idiographic, narrative element when 
exploring how particular health conditions may be experienced by individuals. For example, I was interested in explicating how one woman experienced her particular variant of multiple sclerosis (Finlay, 2003), and how another coped with her particular journey related to receiving a cochlear implant (Finlay and Molano-Fisher, 2008).

There is also a middle position. Halling (2008) accepts both the particular and general by arguing that idiographic research can also be general in that it may well identify general structures of experience. He suggests that phenomenologists engage three levels of analysis: firstly, they look at particular experience, such as one person's story of being disillusioned; secondly, they concern themselves with themes common to the phenomenon (for instance, the nature of disillusionment in general); thirdly, they probe philosophical and universal aspects of being human, by asking what is it about our nature and relationships that creates disillusionment. Halling counsels researchers to move back and forth between experience and abstraction-between experience and reflection-at these different levels.

Building on Halling's formulation, we could say that single cases may offer insight into individual essences (as opposed to typical or universal essences). Husserl (1913/1983) lends support to this position when he says, "Eidetic singularities are essences which necessarily have over them 'more universal' essences as their genre, but do not have under them any particularization in relation to which they would themselves be species" (p. 25). Thus, the choice of a single case may provide sufficient access to a phenomenon depending on the epistemological goals of the project, and the rigor of the eidetic approach adopted. If the research aims for generality across the field, then a wider sample representing different aspects is required. Todres and Galvin (2005) provide an example of research which examines the phenomenon of the "caring narrative" both generically (thematically) and idiographically.

\section{Description or Interpretation?}

Phenomenological research characteristically starts with concrete descriptions of lived situations, often first-person accounts, set down in everyday language and avoiding abstract intellectual generalizations. The researcher proceeds by reflectively analyzing these descriptions, perhaps idiographically first, then by offering a synthesized account, for example, identifying general themes about the essence of the phenomenon. Importantly, the phenomenological researcher aims to go beyond surface expressions or explicit meanings to read between the lines so as to access implicit dimensions and intuitions. ${ }^{3}$ It is this process of "reading between the lines" which has generated uncertainty. To what extent does this approach involve going beyond what the person has said and enter the realm of interpretation?

While all phenomenology is descriptive in the sense of aiming to describe rather than explain, a number of scholars and researchers distinguish between descriptive phenomenology versus interpretive, or hermeneutic, phenomenology. With descriptive (i.e., Husserl-inspired) phenomenology, ${ }^{4}$ researchers aim to reveal essential general meaning structures of a phenomenon. They stay close to what is given to them in all its richness and complexity, and restrict themselves to "making assertions which are 
supported by appropriate intuitive validations” (Mohanty, 1983, cited in Giorgi, 1986, p. 9).

Interpretive phenomenology, in contrast, has emerged from the work of hermeneutic philosophers, including Heidegger, Gadamer, and Ricoeur, who argue for our embeddedness in the world of language and social relationships, and the inescapable historicity of all understanding. "The meaning of phenomenological description as a method lies in interpretation,” says Heidegger (1962, p. 37). Interpretation is not an additional procedure: It constitutes an inevitable and basic structure of our "being-in-theworld”. We experience a thing as something that has already been interpreted.

The division between these descriptive and interpretive variants of phenomenology finds reflection in research. Giorgi (1985), a proponent of a thorough, descriptive Husserlian method, and prolific writer provided the impetus for what became known as the Duquesne approach or tradition (e.g., Wertz, 1985 and Fischer, 1974). Others have embraced more explicitly hermeneutic versions, including the existential, hermeneutic approaches of the Dallas School (Churchill, 2003; Garza, 2007; van Manen, 1990); the open lifeworld approach of Dahlberg et al. (2008); the dialogal approach of Halling and his colleagues (2006); the embodied enquiry approach of Todres (2007); and the Interpretative Phenomenological Analysis in use by Smith and his colleagues (Smith, 2007).

Some scholars, including myself, prefer to see description and interpretation as a continuum where specific work may be more or less interpretive. ${ }^{5}$ Van Manen (1990) suggests that when description is mediated by expression, including nonverbal aspects, action, artwork, or text, a stronger element of interpretation is involved. However, drawing on Gadamer's ideas, he distinguishes between interpretation as pointing to something (interpretation suited to phenomenological description) and interpretation as pointing out the meaning of something by imposing an external framework (such as when offering a psychoanalytic interpretation). Ricoeur has made a similar distinction between the "hermeneutics of meaning-recollection" which, he says, aims for greater understanding of the thing to be analyzed in its own terms, where meanings are brought out and the "hermeneutics of suspicion," which involves deeper interpretations needed to challenge surface accounts (Ricoeur, 1970). ${ }^{6}$ Wertz (2005) picks up the former sense of interpretation when he argues that “'interpretation' may be used, and may be called for, in order to contextually grasp parts within larger wholes, as long as it remains descriptively grounded” (p. 175).

I agree with Langdridge when he notes that in practice there are no hard and fast boundaries between description and interpretation, as "such boundaries would be antithetical to the spirit of the phenomenological tradition that prizes individuality and creativity” (Langdridge, 2008, p. 1131).

\section{Researcher Subjectivity}

Phenomenologists all accept that researcher subjectivity is inevitably implicated in research-indeed, some would say it is precisely the realization of the intersubjective interconnectedness between researcher and researched that characterizes phenomenology. The question at stake is to what extent, and how, researcher subjectivity should be 
marshalled in phenomenological research. As Giorgi (1994) has firmly stated, "nothing can be accomplished without subjectivity, so its elimination is not the solution. Rather how the subject is present is what matters, and objectivity itself is an achievement of subjectivity” (p. 205). Phenomenologists also concur about the need for researchers to engage a "phenomenological attitude." Using this attitude, the researcher strives to be open to the "other" and to attempt to see the world freshly, in a different way. The process has been described variously as disciplined naïveté, bridled dwelling, disinterested attentiveness, and/or the process of retaining an empathic wonderment in the face of the world (Finlay, 2008).

While phenomenologists agree about the need for an open attitude, there remains debate as to whether or not it is necessary to engage the reduction and, if so, what it involves. ${ }^{7}$ In other words, there is a consensus that a change of attitude is required but how that change of attitude is to be affected has generated long debate. One particularly divisive issue for researchers is how much attention they should pay to bringing their own experience to the foreground and reflexively exploring their own embodied subjectivity. To what extent should the researcher's attention be on the noetic (manner of being aware) dimension along with the noematic (object of awareness) dimension?

Some phenomenologists emphasize the reduction as a process of rendering oneself as noninfluential and neutral as possible. Here researchers aim to "bracket" their previous understandings, past knowledge, and assumptions about the phenomenon so as to focus on the phenomenon in its appearing. Novice researchers often misunderstand this process of bracketing as an initial first step where subjective bias is acknowledged as part of the project to establish the rigor and validity of the research. In fact, bracketing involves a process whereby "one simply refrains from positing altogether; one looks at the data with the attitude of relative openness" (Giorgi, 1994, p. 212). More specifically, Ashworth (1996) suggests that at least three particular areas of presupposition need to be set aside: (1) scientific theories, knowledge and explanation; (2) truth or falsity of claims being made by the participant; and (3) personal views and experiences of the researcher which would cloud descriptions of the phenomenon itself. Importantly, this "setting aside" is carried out throughout the research process and is not just a first step.

Other researchers-particularly those of hermeneutic sensibility-would deny it is possible, or even desirable, to set aside or bracket researchers' experience and understandings. They argue instead that researchers need to come to an awareness of their preexisting beliefs, which then makes it possible to examine and question them in light of new evidence (Halling et al., 2006). Researchers need to bring a "critical self-awareness of their own subjectivity, vested interests, predilections and assumptions and to be conscious of how these might impact on the research process and findings" (Finlay, 2008, p. 17). Researchers' subjectivity should, therefore, be placed in the foreground so as to begin the process of separating out what belongs to the researcher rather than the researched. Colaizzi (1973), for example, argues that researcher self-reflection constitutes an important step of the research process, and that preconceived biases and presuppositions need to be brought into awareness to separate them out from participants' descriptions. Gadamer (1975) describes this process in terms of being open to the other while recognizing biases. According to him, knowledge in the human sciences always involves some self-knowledge. 
This openness always includes our situating the other meaning in relation to the whole of our own meanings or ourselves in relation to it ... This kind of sensitivity involves neither "neutrality" with respect to content nor the extinction of one's self, but the foregrounding and appropriation of one's own fore-meanings and prejudices. The important thing is to be aware of one's own bias, so that the text can present itself in all its otherness and thus assert its own truth against one's own fore-meanings. (Gadamer, 1975, pp. 268-269)

Thus, in terms of research, the researcher should shift back and forth, focusing on personal assumptions and then returning to looking at participants' experiences in a fresh way. Wertz (2005) picks up this point when accepting the value of researchers' subjective experience when engaging the epoché of the natural attitude and during the analyses that follow from the phenomenological reduction. He suggests this process allows researchers to:

recollect our own experiences and to empathically enter and reflect on the lived world of other persons... as they are given to the first-person point of view. The psychologist can investigate his or her own original sphere of experience and also has an intersubjective horizon of experience that allows access to the experiences of others. (Wertz, 2005, p. 168)

Following Wertz, in a previous paper I discussed the "phenomenological psychological attitude" as a process of retaining a reductive openness to the world while both restraining and using preunderstandings (Finlay, 2008). Here, the researcher engages a dialectic movement between bracketing preunderstandings and exploiting them reflexively as a source of insight. I suggest the challenge for phenomenological researchers is "to simultaneously embody contradictory attitudes of being 'scientifically removed from,' 'open to' and 'aware of' while also interacting with research participants in the midst of their own experiencing” (Finlay, 2008, p. 3). In this context, researcher reflexivity becomes a "process of continually reflecting upon our interpretations of both our experience and the phenomena being studied so as to move beyond the partiality of our previous understandings” (Finlay, 2003b, p. 108).

One critical danger of engaging researcher reflexivity is that of falling prey to navel gazing. The researcher needs to avoid preoccupation with their own emotions and experience if the research is not to be pulled in unfortunate directions which privilege the researcher over the participant. The focus needs to stay on the research participant and the phenomenon in its appearing. ${ }^{8}$

One possible way of avoiding this trap is to embrace the intersubjective relationship between researcher and researched. "There is a reciprocal insertion and intertwining of one in the other," says Merleau-Ponty (1968, p. 138). As researcher and coresearcher intermingle in "pre-analytic participation" (1968, p. 203), each touches and impacts on the other. If this more explicitly relational approach to phenomenological research is adopted, data is seen to emerge out of the researcher-coresearcher relationship, and is understood to be co-created in the embodied dialogical encounter. ${ }^{9}$ Researchers who support working in this way argue that what we can know about another arises from that intersubjective space between. Examples of this way of working include the research by 
Halling and colleagues (2006) using their dialogal method; Churchill's (2003) research on empathy and communication with a bonobo; and my own relational phenomenology approach (Finlay, forthcoming).

\section{Science or Art?}

All phenomenologists agree on the need to study human beings in human terms. They therefore reject positivist, natural science methods in favor of a qualitative human science approach. As a human science, phenomenology aims to be systematic, methodical, general, and critical (Giorgi, 1997). At the same time, phenomenology also pursues the intertwining of science with art, the imparting of a "poetic sensibility" (Ashworth, personal communication) to the scientific enterprise. In this sense, science blends with the stylistic realms of the humanities. Where phenomenologists disagree, is about how much weight should be accorded to scientific versus artistic elements.

While Giorgi supports the need to have a "certain openness and flexibility" (2008a, p. 42) when it comes to applying his method, he insists that criteria associated with scientific rigor need to be completely respected. Any discerned meanings that come out of the research need to be seen as based on data and achieved through a systematic process of free imaginative variation which allows a kind of internal validity check ${ }^{10}$. A rigorous application of this eidetic variation involves freely changing aspects of the phenomenon in order to distinguish essential features from particular or incidental ones.

Other phenomenologists recommend engaging modes beyond the scientific - art, literary prose, and poetry. They seek methods that retain their concrete, mooded, sensed, imaginative, and embodied nature. Todres, for example, recommends balancing textural and structural forms as part of communicating the aesthetic dimensions of human experience (Todres, 2000, 2007). "Phenomenology, not unlike poetry," says van Manen (1990, p. 13), is a "poetizing project; it tries an incantative, evocative speaking, a primal telling, wherein we aim to involve the voice in an original singing of the world." More recently, he suggests that, "not unlike the poet, the phenomenologist directs the gaze toward the regions where meaning originates, wells up, percolates through the porous membranes of past sedimentations - and then infuses us, permeates us, infects us, touches us, stirs us, exercises a formative affect” (van Manen, 2007, p. 12).

Embracing the Utrecht School tradition, van Manen (1990, 2007) advocates the writing up of phenomenological research as including, ideally, an artistic dimension to "stir our pedagogical, psychological or professional sensibilities" (van Manen, 2007, p. 25). His point highlights how the balance of science-art considerations may shift according to the stage of research.

My belief is that researchers need to attend to the audience they are attempting to communicate with. I value research which has both rigor and resonance. I favor reporting research in whatever mode is going to have the most relevance and impact. Broader political, instrumental, or strategic interests cannot be ignored and it behoves phenomenologists to be reflexively aware of the issues at stake when they are presenting their research (Finlay, 2006a). Sometimes, researcher arguments are best presented by emphasizing the systematic nature of research methods applied and the scientific credentials of the research. At other times, the research may be more memorable when creatively presented. As Behar (1996 as cited in Bochner 2001) once said in reference to 
anthropology, research which “doesn't break your heart just isn't worth doing anymore” (p. 143). A phenomenological text is most successful when readers feel addressed by it (van Manen, 2007):

Textual emotion, textual understanding can bring an otherwise sober-minded person (the reader but also the author) to tears and to a more deeply understood worldy engagement ... To write phenomenologically is the untiring effort to author a sensitive grasp of being itself. (van Manen, 1990, p. 129, 132)

Similarly, I value the communicative power of research that challenges, unsettles, and reverberates with our everyday experience of life.

\section{Modern or Postmodern Paradigms?}

Denzin and Lincoln (1994) assert that the qualitative research field is "defined by a series of tensions, contradictions, and hesitations" which move back and forth between "the broad, doubting postmodern sensibility and the more certain, more traditional positivist, postpositivist, and naturalistic conceptions of this project” (p. 15). Phenomenology is not exempt and the different variants of phenomenology, with their different supporters are caught in, and articulate, this debate.

Phenomenology is sometimes linked to a modernist agenda (Moran, 2000). Some would argue that it offers an inductive methodology to explore human subjectivity systematically in terms of what individuals are really feeling and experiencing. "The main function of a phenomenological description is to serve as a reliable guide to the listener's own actual or potential experience of the phenomena" (Spiegelberg, 1982, p. 694). Here, phenomena are seen to be made up of essences and essential structures which can be identified and described if studied carefully and rigorously enough. In such characterizations, phenomenology can be seen as tending towards being a realist, modernist project where there is a belief in a knowable world with universal properties (at least in some senses), and the aim is to examine the "real world out there."

Others would deny such a simplistic and static view of the phenomenological project. For one thing, attributing fixed immutable properties to human phenomenon is antithetical to the phenomenological project. Philosophers such as Hegel have stressed essence as being a dynamic, dialectical process (Mills, 2005). Also, phenomenological philosophy originally arose, at least in part, in critique of the effects of modern natural human scientific outlook on human beings. ${ }^{11}$ If modernism is aligned to a worldview of an ordered universe ruled by mathematical laws which can eventually be uncovered by science (Polkinghorne, 1992), then phenomenology might be better described as postmodern. In this context, many phenomenologists favor an approach which forgoes any search of true fixed meanings, recognizing that truth is a matter of perspective. Instead, they embrace ambiguity, paradox, descriptive nuance, and a more relational unfolding of meanings (Merleau-Ponty, 1968). They recognize the relative, intersubjective, fluid nature of knowledge. They argue that researcher and participant cocreate the research; that subject-object/self-other are intertwined in intergivenness (Marion, 2002). ${ }^{12}$ In such a paradigm, also, the phenomenological researcher's epistemological authority is disrupted. 
Giorgi (1994) engages elements of this debate by highlighting the epistemological rift between "naturalist" and "phenomenological" paradigms. Following Lincoln and Guba (1985), he describes the naturalist paradigm as claiming multiple, constructed, holistic realities where the knower and known are seen as inseparable and interactive. By then contrasting this paradigm with the phenomenological one, he seems to aim to distance phenomenology from any whiff of relativist postmodern sensibility, while favoring a more modernist and grounded critical realist position ${ }^{13}$ which admits to a reality independent of consciousness (while accepting knowledge of this can only come through study of consciousness). For him, the phenomenological paradigm involves the researcher describing "the nature of reality as taken up and posited by the research participants. This frees the researcher to discover possible reality claims that may be outside his or her a priori specifications" (1994, p. 203). At the same time, Giorgi supports the Husserlian argument which both insists the groundedness of essential structures and accepts the multiplicity and relativity of appearances, ${ }^{14}$ including how these arise in the intersubjective encounter of knower and known-sentiments which seem to come close to the naturalist ideas described by Lincoln and Guba.

The argument about whether phenomenology is a modernist or postmodernist project largely rests on how one defines these concepts (Kvale, 1992). If postmodernism is seen as a perspective that avoids privileging any one authority or method, and denies that any one approach has a clear window on subjectivity/human experience, then many phenomenologists would feel comfortable with this position. In fact, it could said that even Husserl's early work laid the foundations of the postmodern movement by highlighting varying modes of givenness and relativity of appearances (Rodemeyer, 2008). Here, relativity of understanding is stressed instead of relativism as such (Churchill, 2002).

For some, however, postmodernism involves the dissolution of the autonomous, rational subject: the "self is anesthetized" (Mills, 2005, p. 166). Postmodernism is also associated largely with the poststructural, relativist, deconstructive turn where language is seen as an unstable system of referents, thus making it impossible to adequately capture meanings of social actions or texts leading to messy, critical, reflexive, intertextual representations. Supporters of the turn to discourse argue that we cannot simply see participants' talk about their subjective feelings and experiences as a transparent medium through which to glimpse their (internal) worlds. Instead, they say, we need to focus on the performative and constitutive aspect of language which deconstructs any truths concerning a subject's lived experience. While fewer (if any) phenomenologists support this more extreme position, some are working to bridge both modernist and poststructural paradigms. Langdridge (2008), notably, seeks to bring together phenomenology and discursive psychology through Ricoeurian hermeneutics and the application of critical social theory.

The question at stake is: where does phenomenology fit in a postmodern world of ironically shifting boundaries and plurality of perspectives, a world in which construction and deconstruction (of both language and lived embodiment) seem twin imperatives? In the world of qualitative research, where cultural and historical contingency are highlighted, and discursive, poststructuralist, feminist/alternative approaches dominate, is there a plausible space for assertions of authentic selves and universal truths? Or is Langdridge (2008) correct in his critique that phenomenology has continued its mission 
with "scant regard for the issues raised by contemporary philosophers of language and...discursive psychology" (p. 1134)? Can phenomenology embrace the $21^{\text {st }}$ century future without casting regretful backward glances to earlier times?

I believe phenomenology needs to move forward and take its place beyond the modernist-postmodernist divide- the era some call post-postmodernism. The goal-posts and language of psychology (and other disciplines) and the qualitative research field have changed over the last few decades. I think it is necessary for phenomenologists to deal with this "new age where messy, uncertain, multivoiced texts, cultural criticism, and new experimental works will become more common, as will more reflexive forms of fieldwork, analysis and intertextual representation” (Denzin and Lincoln, 1994, p. 15). Ihde's (1993) notion of postphenomenology works well here: "Postphenomenology is precisely the style of phenomenology which explicitly and dare I say 'consciously' takes multidimensionality, multistability, and the multiple 'voices' of things into account- to that degree it bears a family resemblance to the postmodern” (Ihde, 2003, p. 26).

In the current climate, phenomenologists (along with other types of human science researchers) are challenged to recognize that any knowledge produced is contingent, proportional, emergent, and subject to alternative interpretations. At the very least research which is anchored in a more critical realist, modernist position deserves some healthy questioning and can expect critical challenge. The practice of returning to participants to validate researchers' analyses, for example, could be disputed as a problematic throwback to empirical, realist ideals. ${ }^{15}$ At the same time, while phenomenologists may embrace more ironically playful, creative presentations and relativist understandings, they must also ensure they do not lose the speaking, experiencing subject.

I like the message offered by Gendlin (1997): "Let us enter and speak from the realm that opens where all distinctions break down” (p. 269). We need to go beyond the lines drawn by both modernism and postmodernism embracing both and neither.

\section{Conclusion}

In this paper, I have mapped out some of the key areas of confusion and controversy surrounding the application of phenomenology in research. Researchers entering the phenomenological field have to decide for themselves where they stand on questions concerning what paradigm phenomenologists embrace, what their research means, and to what extent interpretation can be involved in the basic descriptive project. They need to work out whether they are seeking normative or idiographic understandings, how to manage researcher subjectivity, and whether phenomenology should be treated as a science, an art, or both.

The competing visions of how to practice phenomenology stem from different philosophical values, theoretical preferences, and methodological procedures. Different forms are demanded according to the type of phenomenon under investigation and the kind of knowledge the researcher seeks. Given a multiplicity of appearances and meanings, surely a multiplicity of methods is also appropriate. Rather than being fixed in stone, the different phenomenological approaches need to remain dynamic and undergo constant development as the field of qualitative research as a whole evolves: "The 
flexibility of phenomenological research and the adaptability of its methods to ever widening arcs of inquiry is one of its greatest strengths” (Garza, 2007, p. 338).

\section{Acknowledgements}

I am indebted to Steen Halling for being open to dialoguing with me, and so generously offering his time to read and comment on an earlier draft of this paper.

\section{Endnotes}

1 Psychological phenomenological approaches can be contrasted with social phenomenological approaches as advanced by Schütz (1967) and others. In this paper, I restrict my discussion to psychological phenomenology.

2 Ashworth (2003, 2006) offers the following list as "fractions" to be employed heuristically in phenomenological lifeworld analysis including: selfhood (meanings of identity, agency, presence, voice); relationships with other people and what others mean to the person (sociality); embodiment (meanings related to one's own sense of one's body); temporality (meanings about past, present and future); spatiality (sense of place, space and bodily scope and possibilities); project (the central concern for the person which reveals itself in the situation); discourse (socially available ways of talking or acting that the person is drawing upon); mood-as-atmosphere (i.e., the feeling tone of the situation).

3 Technically, the term "intuition" is used in Husserlian philosophy to refer to the experienced presence of any object to consciousness, be it perceived or imagined. Intuition, in this sense, can be understood as general understanding of "fleshy actuality" (Marion, 2002) rather than the more common usage definition as a hunch which is tacit and elusive.

4 Other commentators such as von Eckartsberg (1998) call the descriptive version "empirical existential-phenomenological" and contrast it with the "hermeneuticalphenomenological” approach. He suggests a number of researchers follow this tradition including Amedeo Giorgi, Adrian van Kaam, Paul Collaizzi and William Fischer.

${ }^{5}$ Scholars contest the extent of confluence between Husserlian and Heideggerian philosophy. Some argue that Heidegger nudged Husserlian ideas in a different direction; others would say that positing a "continuum" of description and interpretation may be insufficiently attentive to the radical nature of Heidegger's ontological concerns.

${ }^{6}$ Ricoeur's hermeneutics of suspicion go beyond what is given, for example, where Freudian-type analysis brings understanding to bear which is not in the analysand's awareness. Most would argue that the phenomenological spirit is to stay anchored to what is given. 
${ }^{7}$ For Husserl, the reduction delivers the philosopher to the "groping entrance into this unknown realm of subjective phenomena” (1936/1970, p. 161). A number of steps or procedures are involved including: 1) the epoché of the natural sciences; 2) the epoché of the natural attitude; 3) the transcendental reduction; and 4) eidetic reduction. Each of these results in something being put in "brackets" and in a "reduction" of the field which commands one's special focus of attention. The problem remains: how to convert this philosophical method into a practical and empirical one?

${ }^{8}$ Giorgi (1994) offers a more specific argument against the dangers of researchers' overemphasising their own self-awareness and attention to the research relationship-at least in the context of practising a phenomenological method true to Husserl's project. Giorgi would argue the need to keep clear the intentional objects to which the researcher's acts are directed. He asserts that work like Moustakas' (1990) use of “self-dialogue” in his heuristic research approach is not consistent with the phenomenological project as the goal appears to be a researcher's own growth and self-development rather than the explication of a phenomenon. (For this reason, while some phenomenologists might include "heuristic research" as part of the broader field of phenomenological inquiry, others would not).

${ }^{9}$ This kind of approach might be criticized for mixing up the focus of the inquiry (i.e., the phenomenon being investigated moves onto the relationship) and for collapsing therapeutic and research interests (Giorgi, 2008b).

${ }^{10}$ Halling (2008) suggests a slightly different version of this free imaginative variation which he calls "empirical variation”. Here, emphasis is placed on working collaboratively with others where the group members dialogue about their various perspectives allowing the phenomenon to show itself in new ways. In adopting such an approach, Halling is engaged in a distinctly scientific project. However, he also acknowledges something of the art within the process: "The process is an intermingling of receptivity and creativity, of discovering truth and creating truth” (Halling, 2008, p. 168).

${ }^{11}$ For example, Husserl has argued against rationalism promoting naïve objectivism and naturalizing the spirit; Heidegger's work is conceived as antimodernism; and Gadamer argues that not all truth is encapsulated in the scientific method.

12 In the relational-centred approach being developed by Ken Evans and myself (Finlay and Evans, Forthcoming), for example, data is seen to emerge out of the researchercoresearcher relationship-co-created in the embodied dialogical encounter. There is an ambiguity and unpredictability that arises in that intersubjective opening between, where anything can appear. Central to this approach is the need to develop awareness of intersubjective research dynamics and parallel processes (where unconscious processes are being re-enacted) through reflexivity.

13 In between the two poles of realism and relativism is a position variously called "critical realist", "subtle realist" or "new realist". Here researchers tend to be pragmatic. They consider meanings to be fluid while accepting that participants' stories of having an 
illness reflect something of their subjective perceptions of their experience (if not their actual experience) (Finlay, 2006b).

14 There are, as Husserl notes in Ideas I, varying modes of givenness. How the givenness is unfurled depends on the extent of the reduction performed-the more reduction, the more givenness (Marion, 2002). Put in other words, the givenness of lived experience can only be captured (in parts and in different appearances) through the reduction.

${ }^{15}$ Colaizzi (1978) recommends participant verification as a final stage of his seven-step analysis. New data emerging from participants' feedback "must be worked into the final product" (1978, p. 62). Giorgi (2008b), on the other hand, argues that such member checking is both misplaced and not trustworthy, as participants in their natural attitude, cannot confirm the meaning of their experiences; nor do they have the relevant phenomenological skills or disciplinary attitude necessary to adequately judge the analysis.

\section{References}

Ashworth, P.D. (1996). Presuppose nothing! The suspension of assumptions in phenomenological psychological methodology. Journal of Phenomenological Psychology, 27(1), 1-25.

Ashworth, P.D. (2003). An approach to phenomenological psychology: the contingencies of the lifeworld. Journal of Phenomenological Psychology, 34(2), 145-156.

Ashworth, P.D. (2006). Seeing oneself as a carer in the activity of caring. Attending to the lifeworld of the person with Alzheimer's disease. International Journal of Qualitative Studies in Health and Well-being, 1(4), 212-225.

Ashworth, A. and Ashworth, P.D. (2003). The lifeworld as phenomenon and as research heuristic, exemplified by a study of the lifeworld of a person suffering Alzheimer's disease. Journal of Phenomenological Psychology, 34(2), 179-207.

Bochner, P.P. (2001). Narrative’s virtues. Qualitative Inquiry, 7(20), 131-56.

Churchill, S.D. (2002). Stories of experience and the experience of stories: narrative psychology, phenomenology, and the Postmodern Challenge. Constructivism in the Human Sciences, 7, 81-93.

Churchill, S.D. (2003). Gestural communication with a bonobo: Empathy, alterity, and carnal intersubjectivity. Constructivism in the Human Sciences. 8(1), 19-36.

Colaizzi, P.F. (1973). Reflection and research in psychology: A phenomenological study of learning. Dubuque, IA: Kendall Hunt Publishing. 
Colaizzi, P. (1978). Psychological research as the phenomenologist views it. In R. Valle \& King (Eds.), Existential-phenomenological alternatives for psychology (pp.4871). New York: Oxford UP.

Crotty, M. (1996). Phenomenology and nursing research. Melbourne, Australia: Churchill Livingstone.

Dalhberg, K., Dalhberg, H., \& Nyström, M. (2008). Reflective lifeworld research (2nd edition). Lund, Sweden: Studentlitteratur.

Denzin, N.K., \& Lincoln, Y.S. (Eds.). (1994). Handbook of qualitative research. Thousand Oaks, CA: Sage.

Eatough, V., \& Smith, J. (2006). "I was like a wild wild person”: Understanding feelings of anger using interpretative phenomenological analysis. British Journal of Psychology, 97, 483-498.

Finlay, L. (2003a). The intertwining of body, self and world: A phenomenological study of living with recently diagnosed multiple sclerosis. Journal of Phenomenological Psychology, 34(6), 157-178.

Finlay, L. (2003b). Through the looking glass: Intersubjectivity and hermeneutic reflection. In L.Finlay and B.Gough (Eds.), Reflexivity: a practical guide for researchers in health and social sciences. Oxford: Blackwell Publishing.

Finlay, L. (2006a). 'Rigour', 'Ethical integrity' or 'Artistry': Reflexively reviewing criteria for evaluating qualitative research. British Journal of Occupational Therapy, 69(7), 319-326.

Finlay, L. (2006b). Mapping methodology. In L. Finlay and C. Ballinger (Eds.), Qualitative research for allied health professionals: Challenging choices. Chichester, Sussex: John Wiley.

Finlay, L. (2008). A dance between the reduction and reflexivity: Explicating the "phenomenological psychological attitude". Journal of Phenomenological Psychology, 39, 1-32.

Finlay, L. (In press). Ambiguous encounters: A relational approach to phenomenological research. Indo-Pacific Journal of Phenomenology.

Finlay, L., \& Molano-Fisher, P. (2008). 'Transforming' self and world: A phenomenological study of a changing lifeworld following a cochlear implant. Medicine, Health Care and Philosophy, 11(2). (Online version available from 2007). 
Finlay, L., \& Evans, K. (2009). Relational centred research for psychotherapists: Exploring meanings and experience. Chichester, West Sussex: Wiley-Blackwell Publishers.

Fischer, W.F. (1974). On the phenomenological mode of researching 'being anxious'. Journal of Phenomenological Psychology, 4 (2), 405-423.

Gadamer, H.-G. (1975/1996). Truth and Method. [Second revised edition]. London: Sheed and Ward.

Garza, G. (2007). Varieties of phenomenological research at the University of Dallas: An emerging typology. Qualitative Research in Psychology, 4, 313-342.

Gendlin, E.T. (1997). Reply to Liberman: Liberman, K. Meaning reflexivity: Gendlin’s contribution to ethnomethodology. In D.M. Levin (Ed.), Language beyond postmodernism: Saying and thinking in Gendlin's philosophy. Evanston, Illinois: Northwestern University Press.

Giorgi, A. (1975). An application of phenomenological method in psychology. In A. Giorgi, C. Fischer \& E. Murray (Eds.), Duquesne studies in phenomenological psychology: Volume II (pp. 72-79). Pittsburgh, PA: Duquesne UP.

Giorgi, A. (ed.). (1985). Phenomenological and psychological research. Pittsburgh, PA: Duquesne University Press.

Giorgi, A. (1986). Theoretical justification for the use of descriptions in psychological research. In P. Ashworth, A. Giorgi and AJJ de Koning (Eds.), Qualitative research in psychology: Proceedings of the International Association for Qualitative Research. Pittsburgh, PA: Duquesne University Press.

Giorgi, A. (1989). One type of analysis of descriptive data: Procedures involved in following a phenomenological method. Methods, 1, 39-61.

Giorgi, A. (1994). A phenomenological perspective on certain qualitative research methods. Journal of Phenomenological Psychology, 25, 190-220.

Giorgi, A. (1997). The theory, practice, and evaluation of the phenomenological method as a qualitative research procedure. Journal of Phenomenological Psychology, 28(2), 235-260.

Giorgi, A. (2008a). Concerning a serious misunderstanding of the essence of the phenomenological method in psychology. Journal of Phenomenological Psychology, 39, 33-58. 
Giorgi, A. (2008b). Difficulties encountered in the application of the phenomenological method in the social sciences. The Indo-Pacific Journal of Phenomenology, 8(1), 19.

Halling, S. (2008). Intimacy, transcendence, and psychology: Closeness and openness in everyday life. New York: Palgrave Macmillan.

Halling, S., Leifer, M., \& Rowe, J.O. (2006). Emergence of the dialogal approach: Forgiving another. In C. T. Fischer (Ed.), Qualitative Research Methods for Psychology: Introduction through Empirical Studies (pp. 247-278). New York: Academic Press.

Heidegger, M. (1927/1962). Being and Time. Oxford: Blackwell. [1962 text J. Macquarrie \& E. Robinson, Trans.].

Husserl, E. (1970). The crisis of European sciences and transcendental phenomenology. Evanston, Ill.: Northwestern University Press. (Original work published in 1936).

Husserl, E. (1983). Ideas pertaining to a pure phenomenology and to a phenomenological philosophy. First book (F. Kersten, Trans.). The Hague: Martinus Nijhoff. (Original work published 1913).

Ihde, D. (1993). Postphenomenology: Essays in the postmodern context. Evanston, IL: Northwestern University Press.

Ihde, D. (2003). Postphenomenology - Again? Retrieved from http://sts.imv.au/dk/arbejdspapierer/wp3.pdf

King, N., Finlay, L., Ashworth, P., Smith, J.A., Langdridge, D., \& Butt, T. (2008). “Can’t really trust that, so what can I trust?”: A polyvocal, qualitative analysis of the psychology of mistrust. Qualitative Research in Psychology, 5(2), 80-102.

Kvale, S. (Ed.). (1992). Psychology and postmodernism. London: Sage.

Langdridge, D. (2008). Phenomenology and critical social psychology: Directions and debates in theory and research. Social and Personality Psychology Compass, 2, 1126-1142.

Lincoln, Y.S., \& Guba, E.G. (1985). Naturalistic inquiry. Beverley Hills, CA: Sage.

Marion, J.-L. (2002). Being given: Toward a phenomenology of givenness. Stanford, California: Stanford University Press.

Merleau-Ponty, M. (1968). The visible and the invisible (A. Lingis, Trans.). Evanston, IL: Northwestern University Press. (Original work published in 1964). 
Mills, J. (2005). A critique of relational psychoanalysis. Psychoanalytic Psychology, 22(2), 155-188.

Moran, D. (2000). Introduction to phenomenology. London: Routledge.

Moustakas, C. (1990). Heuristic research: Design, methodology, and applications. Newbury Park, CA: Sage Publications.

Polkinghorne, D.E. (1992). A postmodern epistemology of practice. In S. Kvale (Ed.), Psychology and postmodernism (pp. 146-165). London: Sage.

Rodemeyer, L. (2008). The future of phenomenology: Applications. Retrieved from www.newschool.edu/nssr/husserl/Future/Part\%20One/Rodemeyer.html.

Ricoeur, P. (1970). Freud and philosophy: An essay on interpretation (D. Savage, Trans.). New Haven, CT: Yale UP.

Schütz, A. (1967). The phenomenology of the social world (G.Welsh \& F. Lehnert, Trans.). Evanston, IL: Northwestern University Press. (Original work published 1932).

Smith, J.A. (2004). Reflecting on the development of interpretative phenomenological analysis and its contribution to qualitative research in psychology. Qualitative Research in Psychology, 1(1), 39-54.

Smith, J.A. (2007). Hermeneutics, human sciences and health: Linking theory and practice. International Journal of Qualitative Studies on Health and Well-being, 2(1), 3-11.

Smith, J.A., \& Osborn, M. (2003). Interpretative phenomenological analysis. In J.A.Smith (Ed.), Qualitative Psychology. London: Sage.

Spiegelberg, H. (1982). The phenomenological movement. Boston: Martinus Nijhoff.

Todres, L. (2000). Writing phenomenological-psychological description: An illustration attempting to balance texture and structure. Auto/Biography, 3 (1\&2), 41-48.

Todres, L. (2005). Clarifying the life-world: Descriptive phenomenology. In I. Holloway (Ed.), Qualitative research in health care. Buckinghamshire: Open University Press.

Todres, L. (2007). Embodied enquiry: Phenomenological touchstones for research, psychotherapy and spirituality. Basingstoke, Hampshire: Palgrave Macmillan. 
Todres, L., \& Galvin, K. (2005). Pursuing both breadth and depth in qualitative research: Illustrated by a study of the experience of intimate caring for a loved one with Alzheimer's disease. International Journal of Qualitative Methods, 4(2), 1-11.

Todres, L., Galvin, K., \& Dahlberg, K. (2007). Lifeworld-led healthcare: Revisiting a humanising philosophy that integrates emerging trends. Medicine, Health Care and Philosophy, 10, 53-63.

Wertz, F. (1985). Method and findings in a phenomenological study of a complex lifeevent: Being criminally victimised. In A.Giorgi (Ed.), Phenomenology and Psychological Research. Pittsburgh, PA: Duquesne University Press.

Wertz, F. (2005). Phenomenological research methods for counseling psychology. Journal of Counseling Psychology, 52(2), 167-177.

von Eckartsberg, R. (1998). Introducing existential-phenomenological psychology. In R. Valle (Ed.), Phenomenological inquiry in psychology: Existential and transpersonal dimensions (pp. 3-20). New York: Plenum Press.

van Manen, M. (1990). Researching lived experience: Human science for an action sensitive pedagogy. New York: State University of New York Press.

van Manen, M. (2007) Phenomenology of practice. Phenomenology \& Practice, 1(1), 11. 